\title{
THERMODYNAMIC ANALYSIS AND CHARACTERIZATION OF Bi-Cu-Sn ALLOYS AS ADVANCED LEAD-FREE SOLDER MATERIALS FOR HIGH TEMPERATURE APPLICATION
}

\author{
Dragana Živković ${ }^{1}$, Duško Minić ${ }^{2}$, Dragan Manasijević ${ }^{1}$, \\ Iwao Katayama $^{3}$, Nadežda Talijan ${ }^{4}$, Ana Kostov ${ }^{5}$ \\ ${ }^{1}$ University of Belgrade, Technical Faculty, Bor, Serbia \\ ${ }^{2}$ University of Priština, Faculty of Technical Sciences, Kosovska Mitrovica, Serbia \\ ${ }^{3}$ University of Osaka, Graduate School of Engineering, Osaka, Japan \\ ${ }^{4}$ Institute for Chemistry, Technology and Metallurgy, Belgrade, Serbia \\ ${ }^{5}$ Mining and Metallurgy Institute, Bor, Serbia
}

\begin{abstract}
Due to the frequent use of $\mathrm{Cu}$ as a substrate material in electronics, it is of importance to understand the interactions between these solders and the substrate, based on the knowledge of the phase equilibria, thermodynamics and other characteristics of the $\mathrm{Bi}-\mathrm{Cu}-\mathrm{Sn}$ system.

The results of thermodynamic analysis and characterization of Bi-Cu-Sn alloys as advanced lead-free solder materials for high temperature application are presented in this paper. The research inlcudes analytical investigations done by thermodynamic predicting according to GSM method and experimental investigations performed by differential thermal analysis, optical microscopy, hardness and electroconductivity measurements.
\end{abstract}

Keywords: thermodynamics, characterization, $\mathrm{Bi}-\mathrm{Cu}-\mathrm{Sn}$ alloys, lead-free solder materials

\section{INTRODUCTION}

The Bi-Cu-Sn ternary system belongs to the group of systems recently studied from the point of view of interaction of solder with substrates [1-4], although not completely investigated yet.

Few studies of Bi-Cu-Sn ternary system have been performed regarding thermodynamics and phase equilibria. The liquidus projection, Sn-rich part of the system and calculated invariant equilibria of the $\mathrm{Bi}-\mathrm{Cu}-\mathrm{Sn}$ system, extrapolated from binary thermodynamic descriptions, have been presented by Kattner [5]. Enthalpies of mixing of liquid ternary Bi-Cu-Sn alloys at $800{ }^{\circ} \mathrm{C}$ in a large composition range were reported by Ipser at al. [6] and Flandorfer et al. [7]. The activity of bismuth in liquid dilute $\mathrm{Cu}-\mathrm{Sn}-\mathrm{Bi}$ alloys by the method of equilibrium saturation with metal vapour, at $1373 \mathrm{~K}$ was determined by Wnuk and Romanowska [8]. The latest results are the results of Kopyto et al. [9], who performed the electromotive force measurement in order to obtain thermodynamic properties of liquid $\mathrm{Bi}-\mathrm{Cu}-\mathrm{Sn}$ alloys, as well as the results of Manasijević et al. [10].

Having in mind the lack in complete knowledge of the investigated system properties, the results of thermodynamic analysis and characterization of chosen Bi-Cu-Sn ternary alloys - obtained by GSM TD predicting, thermal, structural and mechanical investigations, were presented in this work.

\section{EXPERIMENTAL}

All samples were prepared from $\mathrm{Bi}, \mathrm{Cu}$ and $\mathrm{Sn}$ of $99.99 \%$ purity. The samples were prepared by induction melting under argon atmosphere. The samples were homogenized at $300{ }^{\circ} \mathrm{C}$ for $2 \mathrm{~h}$ and slowly cooled down to the room temperature at a rate less than $5 \mathrm{~K} / \mathrm{min}$.

The DTA measurements were carried out with the Derivatograph ( MOM Budapest ) apparatus under following conditions: argon atmosphere, sample masses about $2 \mathrm{~g}$, heating rate $10 \mathrm{~K} / \mathrm{min}$ and alumina 
as the reference material. Microstructure analysis of investigated samples was performed by optical microscopy, using a Reichert MeF2 microscope. Electrical conductivity was measured using three series of measurements on the standard apparatus SIGMATEST 2.069 (Foerster), while hardness measurements were done according to standard procedure. The samples were prepared without using of etching agens for structure development. All experiments were performed in an air atmosphere.

\section{THEORETICAL FUNDAMENTALS}

Basic theoretic fundamentals of general solution model are given by Chou [11], and present one of the well known thermodynamic predicting methods. The main expression for the calculation of integral molar Gibbs excess energies, $G^{\mathrm{xs}}$, for the system " $i j k$ ", is given as follows:

$\mathrm{G}^{\mathrm{xs}}=\mathrm{x}_{\mathrm{i}} \mathrm{x}_{\mathrm{j}}\left(\mathrm{A}_{\mathrm{ij}}^{\mathrm{o}}+\mathrm{A}_{\mathrm{ij}}^{1}\left(\mathrm{x}_{\mathrm{i}}-\mathrm{x}_{\mathrm{j}}\right)+\mathrm{A}_{\mathrm{ij}}^{2}\left(\mathrm{x}_{\mathrm{i}}-\mathrm{x}_{\mathrm{j}}\right)^{2}\right)+\mathrm{x}_{\mathrm{j}} \mathrm{x}_{\mathrm{k}}\left(\mathrm{A}_{\mathrm{jk}}^{\mathrm{o}}+\mathrm{A}_{\mathrm{jk}}^{1}\left(\mathrm{x}_{\mathrm{j}}-\mathrm{x}_{\mathrm{k}}\right)+\mathrm{A}_{\mathrm{jk}}^{2}\left(\mathrm{x}_{\mathrm{j}}-\mathrm{x}_{\mathrm{k}}\right)^{2}\right)+\mathrm{x}_{\mathrm{k}} \mathrm{x}_{\mathrm{i}}\left(\mathrm{A}_{\mathrm{ki}}^{\mathrm{o}}+\mathrm{A}_{\mathrm{ki}}^{1}\right.$ $\left.\left(\mathrm{x}_{\mathrm{k}}-\mathrm{x}_{\mathrm{i}}\right)+\mathrm{A}_{\mathrm{ki}}^{2}\left(\mathrm{x}_{\mathrm{k}}-\mathrm{x}_{\mathrm{i}}\right)^{2}\right)+\mathrm{fx}_{\mathrm{i}} \mathrm{x}_{\mathrm{j}} \mathrm{x}_{\mathrm{k}}$

where $\mathrm{A}_{\mathrm{ij}}^{\mathrm{o}}, \mathrm{A}_{\mathrm{ij}} \mathrm{A}^{2} \mathrm{~A}_{\mathrm{ij}}$ are parameters for binary system "ij" independent of composition, only relying on temperature, which have been used in the regular type equation, such as:

$\mathrm{G}^{\mathrm{xs}}{ }_{\mathrm{ij}}=\mathrm{X}_{\mathrm{i}} \mathrm{X}_{\mathrm{j}}\left(\mathrm{A}_{\mathrm{ij}}^{\mathrm{o}}+\mathrm{A}_{\mathrm{ij}}^{1}\left(\mathrm{X}_{\mathrm{i}}-\mathrm{X}_{\mathrm{j}}\right)+\mathrm{A}_{\mathrm{ij}}^{2}\left(\mathrm{X}_{\mathrm{i}}-\mathrm{X}_{\mathrm{j}}\right)^{2}+\ldots+\mathrm{A}_{\mathrm{ij}}^{\mathrm{n}}\left(\mathrm{X}_{\mathrm{i}}-\mathrm{X}_{\mathrm{j}}\right)^{2}\right)$

where $X_{i}$ and $X_{j}$ indicate the mole fraction of component "ij" and " $\mathrm{j}$ " in "ij" binary system, as:

$\mathrm{X}_{\mathrm{i}(\mathrm{ij})}=\mathrm{x}_{\mathrm{i}}+\mathrm{x}_{\mathrm{k}} \xi_{\mathrm{ij}}$.

The function $\mathrm{f}$ is the ternary interaction coefficient expressed by

$\mathrm{f}=\left(2 \xi_{12}-1\right)\left\{\mathrm{A}_{12}^{2}\left(\left(2 \xi_{12}-1\right) \mathrm{x}_{3}+2\left(\mathrm{x}_{1}-\mathrm{x}_{2}\right)\right)+\mathrm{A}_{12}^{1}\right\}+\left(2 \xi_{23}-1\right)\left\{\mathrm{A}_{23}^{2}\left(\left(2 \xi_{23}-1\right) \mathrm{x}_{1}+2\left(\mathrm{x}_{2}-\mathrm{x}_{3}\right)\right)+\mathrm{A}_{23}^{1}\right\}+$

$\left(2 \xi_{31}-1\right)\left\{\mathrm{A}_{31}^{2}\left(\left(2 \xi_{31}-1\right) \mathrm{x}_{2}+2\left(\mathrm{x}_{3}-\mathrm{x}_{1}\right)\right)+\mathrm{A}_{31}^{1}\right\}$,

where $\xi_{\mathrm{ij}}$ are the similarity coefficients, defined to be calculated according to the procedure of general solution model [11].

In all given equations, $\mathrm{G}^{\mathrm{xs}}$ and $\mathrm{G}^{\mathrm{xs}}{ }_{\mathrm{ij}}$ correspond to the integral molar excess Gibbs energies for ternary and binary systems, respectively, while $\mathrm{x}_{1}, \mathrm{x}_{2}, \mathrm{x}_{3}$ correspond to the mole fraction of components in investigated ternary alloys.

\section{RESULTS AND DISCUSSION}

The thermodynamic calculation in ternary $\mathrm{Cu}-\mathrm{Bi}-\mathrm{Sn}$ system was performed along the line of a constant $\mathrm{Bi}: \mathrm{Cu}$ molar ratio of $1: 1,1: 3$ and $3: 1$ at the temperature of $1273 \mathrm{~K}$.

The starting data for the calculation according to general solution model were taken from [12]. The Redlich-Kister parameters (in $\mathrm{J} / \mathrm{mol}$ ) for the liquid phase of the constitutional binaries in the investigated $\mathrm{Cu}-\mathrm{Bi}-\mathrm{Sn}$ system are presented in Table 1. Based on these starting data, similarity coefficients were determined according to the procedure of general solution model [11] and their values were: $\xi_{\mathrm{Cu}-\mathrm{Bi}}=0.108, \xi_{\mathrm{Bi}-\mathrm{Sn}}=0.692$ and $\xi_{\mathrm{Sn}-\mathrm{Cu}}=0.787$.

Table 1. Redlich-Kister parameters for the liquidus phase of constitutional binaries (a) and calculated similarity coefficients at different temperatures (b) in the ternary system Bi-Cu-Sn

\begin{tabular}{|c|c|c|c|}
\hline System & $\mathrm{Bi}-\mathrm{Cu}$ & Bi-Sn & $\mathrm{Cu}-\mathrm{Sn}$ \\
\hline $\mathrm{A}_{\mathrm{ij}}^{0}(\mathrm{~T})$ & $20747.5-5.85 * \mathrm{~T}$ & $500+1.5 * \mathrm{~T}$ & $-9002.8-5.8381 * \mathrm{~T}$ \\
\hline $\mathbf{A}_{i j}^{1}(\mathbf{T})$ & $-4925+2.55 * \mathrm{~T}$ & $-100-0.135^{*} \mathrm{~T}$ & $-18936.316+2.339 * \mathrm{~T}$ \\
\hline$A_{i j}^{2}(T)$ & $4387.5-2.3 * \mathrm{~T}$ & 1 & $-14122.6+52.942 \mathrm{~T}-7.057 \mathrm{~T} \ln \mathrm{T}$ \\
\hline
\end{tabular}

Further calculation was carried out for selected alloys in selected sections in the Bi-Cu-Sn ternary system at investigated temperature $1273 \mathrm{~K}$, according to the fundamentals of general solution model [11], as given by Eqs.(1-3). The results of the predictions, including integral molar Gibbs excess energy and calculated tin activities, are given in Table 2 and Fig.1, respectively.

Table 2. Integral molar Gibbs excess energies, $G^{x s}$ (in J/mol) obtained by GSM

\begin{tabular}{|c|c|c|c|c|c|c|c|c|c|}
\hline \multirow{2}{*}{ Section } & \multicolumn{10}{|c|}{ Tin molar content, $\mathbf{x S n}$} \\
\cline { 2 - 11 } & 0.1 & 0.2 & 0.3 & 0.4 & 0.5 & 0.6 & 0.7 & 0.8 & 0.9 \\
\hline $\mathbf{B i}-\mathbf{C u}=\mathbf{1 : 1}$ & 1580 & 494 & -128 & -446 & -578 & -608 & -578 & -495 & -326 \\
\hline $\mathbf{B i}: \mathbf{C u}=\mathbf{1 : 3}$ & 128 & -1321 & -1979 & -2133 & -2000 & -1734 & -1417 & -1067 & -634 \\
\hline $\mathbf{B i}: \mathbf{C u}=\mathbf{3 : 1}$ & 1566 & 1010 & 650 & 419 & 265 & 152 & 63 & 5 & -36 \\
\hline
\end{tabular}



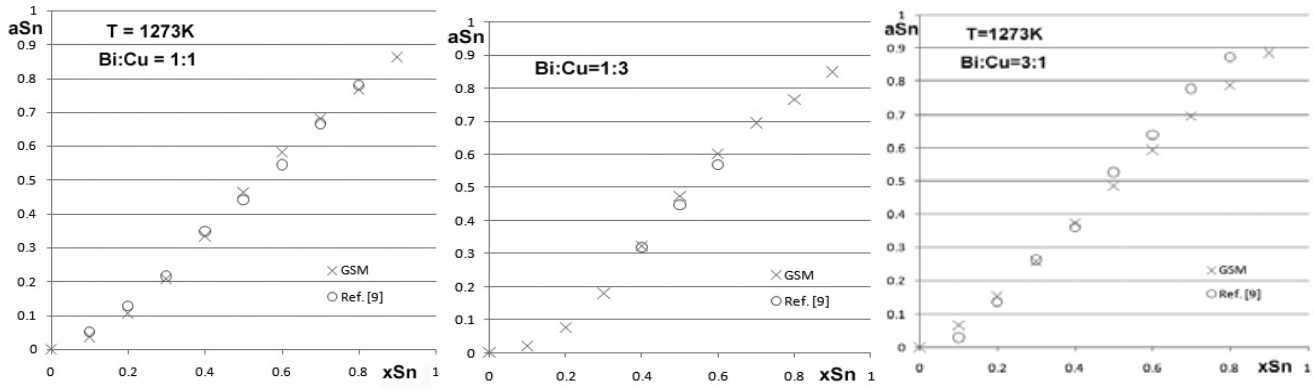

Figure 1. Tin activities in selected section of the Bi-Cu-Sn system at $1273 \mathrm{~K}$ obtained by GSM

It may be noticed that there is a slight deviation from Raoult law in all three investigated sections, with a small change at a certain tin composition from negative to positive behaviour. Also, comparison of calculated results from this work with experimental literature data [9], shown in Fig.1, indicates to a good mutual agreement. Having in mind the lack of complete experimental thermodynamic results for searched system, it is important to know that general solution model can adequately describe its thermodynamic behaviour.

In the frame of the alloys characterization, thermal analysis has been done and the results of the measurements are given in Table 3, including characteristic phase transition temperatures - liquidus and other peak temperatures obtained by DTA in three investigated $\mathrm{Bi}-\mathrm{Cu}-\mathrm{Sn}$ sections.

Table 3. DTA results for the investigated alloys of the Bi-Cu-Sn ternary system

\begin{tabular}{|c|c|c|}
\hline \multirow{2}{*}{ Sample composition (in at\%) } & \multicolumn{2}{|c|}{ T (K) } \\
\cline { 2 - 3 } & Liquidus temperature & Other peak temperature \\
\hline Bi:Cu=1:1 & 996 & $413,482,506,948$ \\
\hline Bi40Cu40Sn20 & 949 & 417,473 \\
\hline Bi35Cu35Sn530 & 938 & $413,466,526$ \\
\hline Bi30Cu30Sn40 & 865 & 417,560 \\
\hline Bi25Cu25Sn50 & 757 & $413,457,632$ \\
\hline Bi15Cu15Sn70 & & $414,473,501$ \\
\hline Bi:Cu=3:1 & 920 & 414 \\
\hline Bi60Cu20Sn20 & 760 & 412,460 \\
\hline Bi30Cu10Sn60 & 619 & 471 \\
\hline Bi15Cu5Sn80 & & 413,546 \\
\hline Bi:Cu=1:3 & 938 & 413,575 \\
\hline Bi17.5Cu52.5Sn30 & 918 & 413,642 \\
\hline Bi15Cu45Sn40 & 861 & \\
\hline Bi7.5Cu37.5Sn050 & 752 & \\
\hline
\end{tabular}

The results of optical microscopy are presented in Fig.2, while the results of electroconductivity and hardness measurements are shown in Fig.3.

\section{CONCLUSION}

The results of thermodynamic analysis and characterization of selected alloys in $\mathrm{Bi}-\mathrm{Cu}-\mathrm{Sn}$ system are shown in this paper. The results of GSM predicting showed good mutual agreement with available literature data, while other experimentally obtained results of DTA, LOM, electroconductivity and hardness measurements present a contribution to the better knowledge of that potential lead-free solder material for high temperature application.

\section{ACKNOWLEDGEMENT}

The results presented in this work were done in the frame of project ON142043 financed by the Ministry of Science and Technological Development, Republic of Serbia and EU project COST MP0602. 

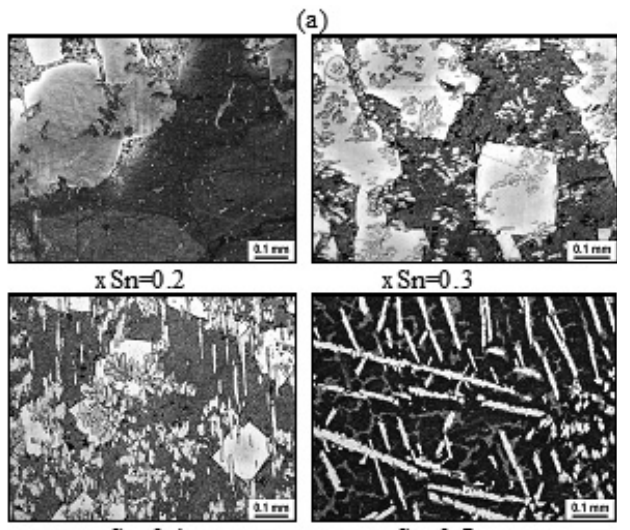

$\mathrm{x} \mathrm{Sn}=0.3$
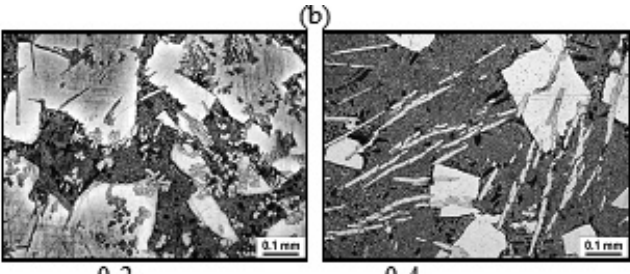

0.2

0.4

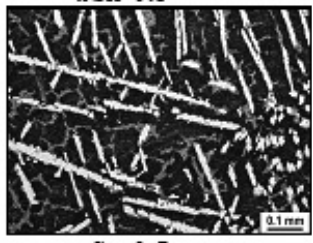

$x \mathrm{Sn}=0.7$
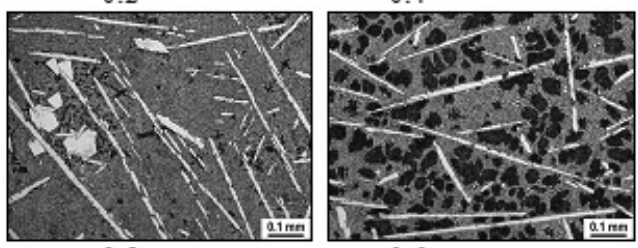

0.5

0.6

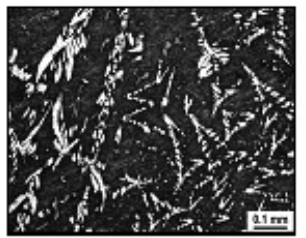

$\mathrm{x} \mathrm{Sn}=0.8$

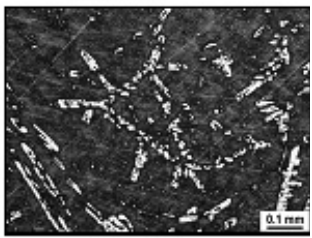

$x \mathrm{Sn}=09$

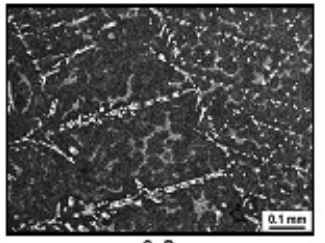

0.8

Figure 2. Microphotographs of the alloys in the sections with molar ratio $\mathrm{Bi}: \mathrm{Cu}=1: 1$ (a) and 3:1 (b)
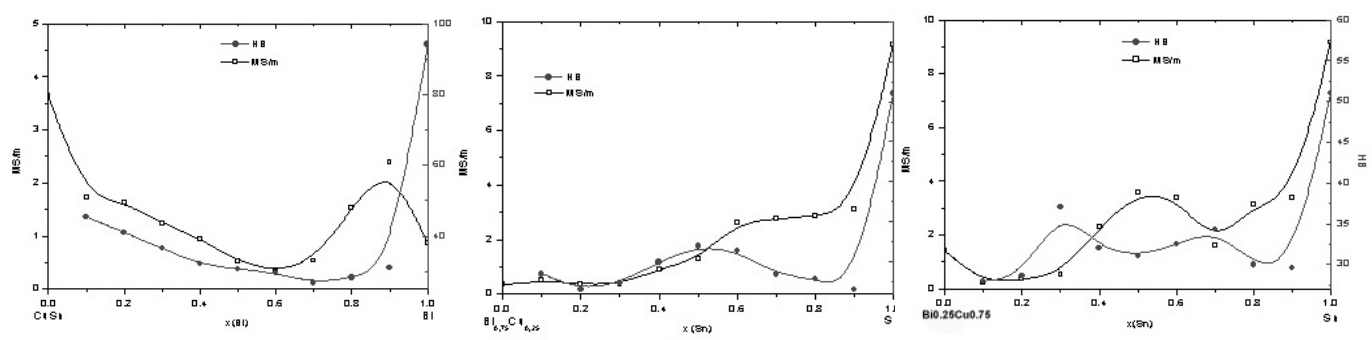

Figure 3. Hardness and electroconductivity of the alloys in the sections with molar ratio $\mathrm{Bi}: \mathrm{Cu}=1: 1$ (a), 3:1 (b) and 1:3 (c)

\section{REFERENCES}

[1] J.F. Li, S.H. Mannan, M.P. Clode, D.C. Whalley, D.A. Hutt, Acta Materialia, 54 (11) (2006) 2907.

[2] L.Zang, Z. Yuan, H. Zhao, X. Zhang, Materials Letters, 63 (23) (2009) 2067.

[3] S. Min, J. Park, J. Lee, Materials Letters, 62 (29) (2008) 4464.

[4] H.W.Miao, J.G. Duh, Materials Chemistry and Physics, 71 (3) (2001) 255.

[5] http://matdl.org/repository/view.php?pid=matdl:547

[6] H. Ipser, H. Flandorfer, Ch. Luef, C. Schmetterer, U. Saeed, J Mater Sci: Mater Electron, 18 (2007) 3-17.

[7] H.Flandorfer, A. Sabbar, C.Luef, M.Rechchach, H.Ipser, Thermochimica Acta, 472 (1-2) (2008) 1-10.

[8] G. Wnuk, J. Romanowska, Archives of Metallurgy and Materials, 51 (4) (2006) 593-597.

[9] M.Kopyto, G.Garzel, L.Zabdyr, J.Min.Metall., 45B (1) (2009) 95-100.

[10] D.Manasijević, D.Minić, D.Živković et al., 8th Scientific/Research Symposium with International Participation - MNM'10“'Zenica (BiH), 27-28 April 2010, Book of Abstracts, pp.28.

[11] Chou K.C., CALPHAD, 19 (3) (1995) 315.

[12] COST531 Thermodynamic Database, Vs.3.0 (2008) 